\title{
In the prevery
}

Welcome to the July/August 2010 issue of CERL News. With summer break in full swing at many institutions, academic and research librarians often take the opportunity of the slightly slower "regular" work load to get caught up on projects. In my days a college librarian, that often meant updating pathfinders. In this month's issue, Ron Gilmour examines putting "Old wine in new skins" and provides advice for creating and updating successful 21st-century Web guides.

Tools such as LibGuides have definitely streamlined the process of providing guides to library resources. But some libraries are taking these tools beyond the usual topic or course-based guides. Librarians from Bloomington University of Pennsylvania provide an overview of a project "Using LibGuides for an information literacy tutorial."

Sharon Weiner puts out a call to action for improving integration of "Information literacy" instruction across campus, based on the findings of a recent Project Information Literacy report.

Getting out of the library and working with other areas is essential to improving student's information literacy and research skills. Leslie J. Foutch discusses a collaboration between the library and Vanderbilt University's Writing Studio in her article "Joining forces to enlighten the research process." Looking outside of academia can also provide inspiration, as Katie Maier-O'Shea found when she volunteered at her local public library.

Make sure to check out all of the other great information in this month's issue, including a scholarly communication column on "Open access at the University of Kansas," an examination of "Mobbing in the library workplace," and the latest edition of Job of a Lifetime.

Thanks as always for reading the News and have a great summer!

-David Free, editor-in-chief dfree@ala.org

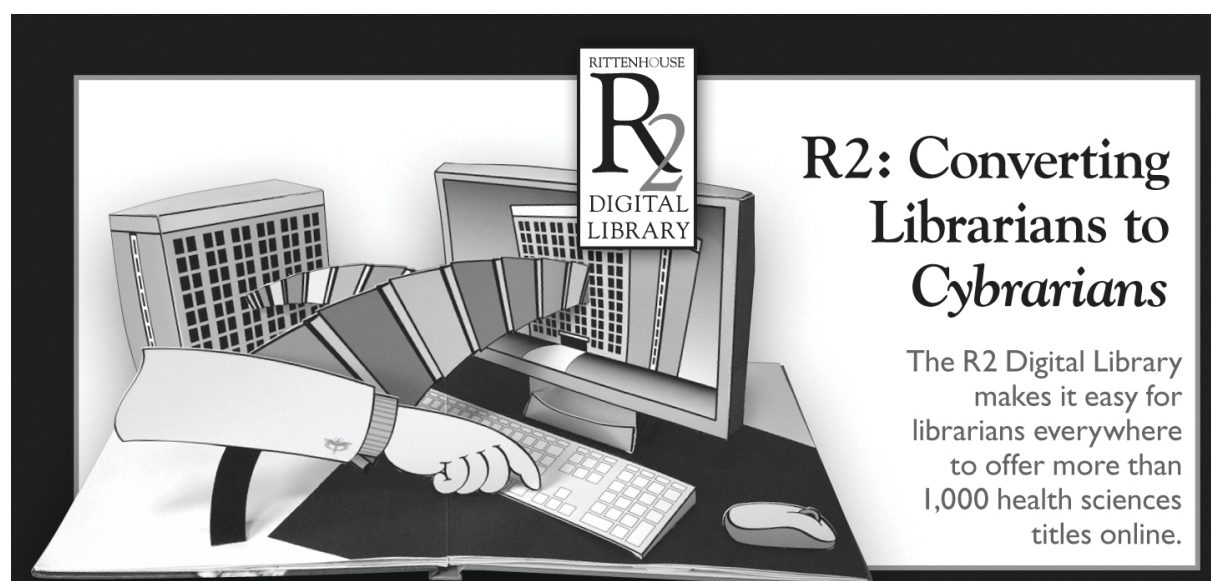

SAVE MONEY.

Avoid "all-or-nothing" prices. Add more titles immediately with the push of a button.

\section{SAVE TIME.}

Easy-to-use interface. If you can surf the web, you can use R2.

MANAGE SMARTLY.

Monitor usage statistic in real time, so you can make informed decisions.

Rittenhouse

BOOK DISTRIBUTORS
5II Feheley Dr., King of Prussia, PA 19406 • 800-345-6425 www.r2library.com • www.rittenhouse.com 